\title{
Association of Lifestyle Variables and Anthropometric Measurements among Breast Cancer Patients at the University College Hospital, Ibadan
}

\author{
Emmanuel O. Adesuyi, Samuel A. Olawoore, Adebayo Komolafe, and Oluwatobi B. Kolawole
}

\section{ABSTRACT}

Globally, breast cancer is the commonest cause of cancer death and the most frequently diagnosed cancer among women. This study aim to assess lifestyle indices and anthropometric measurements among breast cancer patients at the University College Hospital, Ibadan. This was a descriptive cross-sectional study. 250 respondents were recruited for the study after anticipating a non-response rate of $10 \%$. Simple random sampling technique was used to select participants for the study. A self-designed openended questionnaire was adopted. Two hundred and fifty copies were distributed and retrieved. Data collected were analyzed and descriptive statistics presented in tables and charts while hypothesis were tested using multinomial logistic regression at $\mathbf{0 . 0 5}$ level of significance. Majority 150 $(60 \%)$ of the respondents were within the age range of 45-64 years and 137 $(54.8 \%)$ of them had tertiary education. The mean: Age was 50 years, weight before, after diagnosis were $72.8 \mathrm{~kg}$ and $69.2 \mathrm{~kg}$, BMI before, and after diagnosis were 28.65 and 27.21 respectively, waist hip ratio (WHR) was 0.91 and conicity index was 1.37 . All the respondents $250(100 \%)$ were involved in different type of exercise before diagnosis but only $100(40 \%)$ continued after diagnosis. Out of about $20(8 \%)$ respondents who were smoking before diagnosis, only $15(6 \%)$ continued smoking after diagnosis and out of the $95(38 \%)$ of those who consumed alcohol before diagnosis, only $90(36 \%)$ continued after diagnosis. There were statistically significant associations between BMI, WHR, obesity and selected lifestyle variables before and after diagnosis at $\mathbf{p} \leq \mathbf{0 . 0 5}$. Conclusively, lifestyle variables were found to have significant influence on the anthropometric measures of the body of breast cancer patients regardless of their morbid or pre-morbid state. This study further ratifies the obesity predictive capacity of the body's anthropometric measurements, which is largely influenced by various lifestyle indices and perhaps other unknown variables such as genetics and environmental influence. Even though a little modification of certain lifestyles were recorded after respondents were being diagnosed with breast cancer, this undeniably could be as a result of fear of disease outcomes, personal effort to get knowledge or the impact of health education from care givers. It was recommended that caregivers should ensure proper health education of clients on lifestyle changes in order to have a safer life and exclude known factors that can predispose them to breast cancer.

Keywords: Anthropometric, breast cancer, genetic, lifestyle, obesity.
Submitted: August 1, 2021

Published: August 29, 2021

ISSN: 2593-8339

DOI: $10.24018 /$ ejmed.2021.3.4.997

\section{E. O. Adesuyi}

Birmingham City University, United Kingdom.

Institute of Nursing Research, Nigeria (e-mail:

emmanuel.adesuyi@bcu.ac.uk)

S. A. Olawoore

LAUTECH Teaching Hospital, Ogbomoso, Oyo State

Institute of Nursing Research, Nigeria

(e-mail: fortunecompanion@gmail.com)

A. Komolafe

Department of Biochemistry, Ladoke Akintola University of Technology, Nigeria. (e-mail:

komolafeadebayo1234@gmail.com)

O.B Kolawole

Oxford University NHS, John Radcliffe Hospital, England.

(e-mail: oluwatobi.kolawole@ouh.nhs.uk)

\section{INTRODUCTION}

Cancer is a group of disease initiated when cells of the human body begin to grow uncontrollable and spread to other parts of the body. Most types of cancer cells eventually form a lump or mass called a tumor and are named after the part of the body where the tumor originates. Medically it is a malignant neoplasm which accumulate a

heavy mass around it, known as tumor and may cause death if not cured. The tumors are generally of two types viz benign and malignant. The benign tumor does not invade the nearby part tissues of body and hence present as a non-cancerous cyst only while malignant tumor invades the nearby parts of body and causes cancer [1].

Breast cancer is the most common cause of cancer death and the most frequently diagnosed cancer among women in 140 of 193 countries worldwide. In developed countries, however, mortality from breast cancer has been on the decline despite the higher incidence of breast cancer, this may be due to the high level of recognition that cancer screening received, and lifestyle modifications deduced from research findings [2]. The incidence of breast cancer is increasing 
globally and more rapidly in societies that hitherto enjoyed a low incidence of the disease, such as African countries [3]. In a more recent retrospective study by [4], reported in 2014 from the northern part of Nigeria, the prevalence rate of breast cancer was found to be 10.4 cases per 100,000 . Owing to its low survival rate, the WHO has listed the cancer as one of the most dreadful disease which causes about $13 \%$ of world mortality [5].

\section{A. Empirical Studies}

Women with BMI of $25.0 \mathrm{~kg} / \mathrm{m}^{2}$ or WHR of 0.83 were at the lowest risk of late all-cause mortality, whereas those with BMI beyond the range of $22.1-28.7 \mathrm{~kg} / \mathrm{m}^{2}$ or WHR beyond the range of $0.81-0.86$ had a higher risk. ER, stage or menopausal status did not modify the effect of post-diagnosis BMI or WHR on the outcomes [6].

Obesity has been consistently found a negative prognostic factor in breast cancer patients, but the effect of underweight remains unclear. In this study, we found that women with BMI $<22.1 \mathrm{~kg} / \mathrm{m}^{2}$, including those underweighted and patients with normal-low BMI, had elevated risk of death. As all patients in our study were long-term survivors who went through long course of disease, the inhibited immune system and cytokine reactions caused by chronic malnutrition [7], and weight loss resulted from illness might explain the result.

In 24,698 Korean breast cancer patients, underweighted $\left(<18.5 \mathrm{~kg} / \mathrm{m}^{2}\right)$ patients were observed to have a significantly poorer overall survival and shorter time to distant and local recurrence compared with patients with normal weight (18.5$24.9 \mathrm{~kg} / \mathrm{m}^{2}$ ) [6]. The study conducted in 20,090 Japanese cases also observed a significant underweight-mortality association in all and postmenopausal breast cancer patients [8]. Subjects' adolescents' girls baudi village of west Medinipur, 1000 girls of 10 years to 18 years, different anthropometric measurements are taken for that study, Girls are divided into 2 categories pre-menarcheal girls and postmenarcheal girls, the study showed if there are any effect abdominal fat on menarche. The height, weight and waist hip circumferences were measured, percent body fat has positive correlation with conicity index, but Conicity mean with every age was minimally increased, but body mass index had negative correlation with conicity index. Conicity index is indicator central obesity but mean of this conicity index is low so that study girls not centrally obese [9].

There were suggestions that increased adiposity is associated with a reduced risk of premenopausal breast cancer at a greater magnitude than previously shown and across the entire distribution of BMI. The strongest associations of risk were observed for BMI in early adulthood [10]. This study therefore intends to investigate the association between lifestyle variables and anthropometric variables among breast cancer patients at the University College Hospital, Ibadan.

\section{Methodology}

\section{A. Study Design}

This study used a descriptive cross-sectional design.

\section{B. Study Population}

This comprised of women aged 25-70 years that was previously or newly diagnosed of breast cancer and have come to seek medical attention in the hospital.

\section{Inclusion Criteria}

This included all women ages between 25 and 70 years diagnosed of breast cancer who have come to the hospital to seek medical care. It also ensured that such women could give consent and understand Yoruba and/or English language for ease of data collection.

\section{Exclusion Criteria}

This includes any woman: without breast cancer, below 25 years of age, who are not willing to participate in the study and refused to sign the consent form or has problems retrieving details of care received.

\section{E. Sample Size Estimation}

A sample size (n) of 250 inclusive of a non-response rate of $10 \%$ was determined using the G-power software version 3.1.9.2 where $\rho$ is the effect size from previous studies$23.4 \%$ [11], thus $\rho$ is 0.234 .

\section{F. Sampling Technique}

Stage 1: Sampling of the study settings was done purposively. Only wards/units that admit breast cancer patients were selected for the study.

Stage 2: However, in each unit/ward, simple randomized sampling was used to select participants for this study so that all available breast cancer patients can be given equal chances of being selected.

\section{G. Validity}

Validity of the instrument was achieved through the use of relevant literature and by presenting the questionnaire to researcher's supervisor, statistician and other research experts who reviewed the items on the questionnaire in order to ensure clarity and the suitability of items. Suggestions of which was used to modify the instrument so as to be able to elicit responses that will provide adequate answers for the research questions and serve as a basis of conclusion for the research hypotheses.

\section{H. Reliability}

Reliability of the research instrument was ensured by using test-retest method. This will be done by administering the proposed questionnaire to patients living with breast cancer attending the State Hospital, Ring Road Adeoyo, Ibadan in which $10 \%$ of 250 (25) respondents was randomly selected, informed consent taken and data from the retrieved questionnaires was coded, organized, and analyzed to determine the internal consistency of the instrument. The Cronbach's alpha coefficient was used to check the instrument reliability, the result was 0.858 and unnecessary parts of the instrument were removed.

\section{Ethical Considerations}

The study considered various steps to ensure that the data collection process adhered to traditional ethical research standards. Approval was granted by the institute of advanced medical research and training (IAMRAT) college of medicine, university of Ibadan for the research to be 
conducted. An introductory letter was taken to the Chief Medical Advisory Committee of the hospital to seek permission for the patients of the hospital to participate in the research. Full consent was obtained from the participants prior to the study. Ethical principles such as beneficence, nonmaleficence, autonomy, and confidentiality were ensured.

\section{J. Confidentiality of Data}

Confidentiality was ensured throughout the process of data collection, management, storage, and analysis. Respondents were not required to include their name(s) or contact on the questionnaire and the data obtained was used solely for the purpose of this research.

\section{RESULTS}

Majority of the respondents were traders and housewives while mid-way some were farmers, secretaries and jobless. The least occupation amongst the respondents includes clergy, clerk, food vendor, immigration, keke driver, lecturer, nurse, and student. Above two-third of the respondents were married while the rest were single and widowed. This may suggest that majority of the breast cancer patients were married.

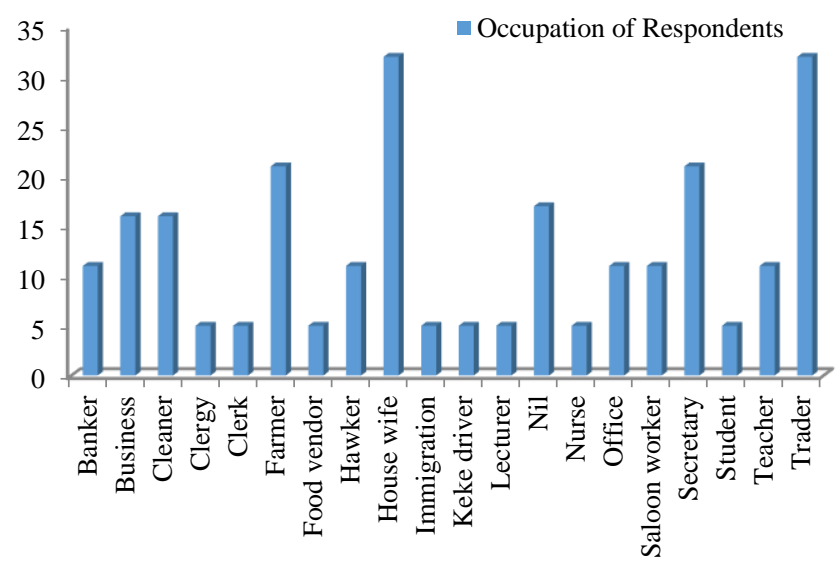

Fig. 1. Respondent's Demograph.

\section{A. Anthropometric Parameters (BMI, Waist Hip Ratio and Obesity Status) of the Respondents Prior to Diagnosis} from the Patient and Recorded History from File Records

The waist hip ratio of the respondents before being diagnosed of breast cancer could not be estimated however, the BMI was determined since the respondents could recall their previous weights and heights and for those who could not, it was gotten from their case files.

From Table I, the mean or average BMI before diagnosis is 28.66. This value is quite high and suggests an alarming level of beyond normal weight in individuals even before being diagnosed of cancer. This is consistent with [12] who demonstrated that overweight (body mass index, BMI: 25$\left.<30 \mathrm{~kg} / \mathrm{m}^{2}\right)$ and obesity $\left(30 \mathrm{~kg} / \mathrm{m}^{2}\right)$ are established cancer risk factors. Obesity status of the respondent's using BMI is as follows from Table I, one-quarter of the respondents had class II Obesity, one-third had normal weight, another one-third was overweight, one-fifth belonged to class I Obesity and the rest had high risk obesity. Since majority of the respondents were already navigating the plain of obesity from being overweight even before diagnosis of breast cancer is made, this may suggest an association between fat accumulation or obesity and the onset of breast cancer.

TABLE I: OBESITY CLASSIFICATION OF RESPONDENTS USING BMI, WHR AND CI

\begin{tabular}{lcccc}
\hline \hline \multicolumn{2}{c}{ Variables } & Level (N=250) & Frequency & Percentage \\
\hline \hline BMI & Obesity & Class I Obesity & 43 & 17.2 \\
classification & before & Class II Obesity & 53 & 21.2 \\
diagnosis & & High risk Obesity & 11 & 4.4 \\
& & Overweight & 91 & 36.4 \\
& & Normal weight & 52 & 20.8 \\
BMI & Obesity & Class I Obesity & 37 & 14.8 \\
classification & after & Class II Obesity & 21 & 8.4 \\
diagnosis & & Normal weight & 85 & 34.0 \\
& & Overweight & 107 & 42.8 \\
Obesity Classification & Obese & 53 & 21.2 \\
with WHR & Not Obese & 197 & 78.8 \\
Obesity classification & Obese & 213 & 85.2 \\
with conicity index & Not Obese & 37 & 14.8 \\
\hline \hline
\end{tabular}

\section{B. Assessing the Lifestyle Variables before and after} Diagnosis of Breast Cancer

From Table II, about two-thirds of the respondents said their job is stressful before diagnosis. About two-thirds of the respondents said before diagnosis they spent below 8 hours on physical activities while after diagnosis, majority or almost all the respondents said they spent below 8 hours in physical activities. Over half of the respondents before diagnosis said they spent 8-10 hours on exercise while after diagnosis, one-third of the respondents said they spent 8-10 hours on exercise. Over half of the respondents before diagnosis said they spent 3-4 hours in a day on a nap while one-third said they never took a short nap in a day, while after diagnosis above average said they spent half hour to 2 hours in a day on a short nap while one quarter said they never took a nap [13], opined that woman who get regular physical activity have a 10\%-20\% lower risk of breast cancer compared to women who are inactive [14] discovered that a greater reduction in risk is associated with increasing amounts of exercise and more vigorous activity; however, even smaller amounts of exercise, including walking, appear beneficial.

From Table III, close to all the respondents said they do not smoke while only very few of them smoke. Amongst the few smokers, most of them smoke cigarettes before and after being diagnosed of breast cancer. Most of the smokers smoke between 1-2 sticks of cigarette per day before and after diagnosis and close to all of the smokers said they have been smoking for a period of 10 years and above. A review by American Cancer Society researchers found that women who initiated smoking before the birth of their first child had a $21 \%$ higher risk of breast cancer than women who never smoked [15].

From Table IV, about two-third of the respondents said they do not take alcohol before diagnosis while the rest does but after diagnosis, a very slight increase was noticed amongst those who do not take alcoholic drink and a proportionate decrease in those who drink alcohol, this could be because of certain lifestyle modification that ensues as some of them visit the hospital or care givers. Amongst the few who drink alcohol, majority of them said they take it when mixed with bitters of herbs while the rest takes it in beer 
and its pure form before and after diagnosis. Majority of this alcohol drinkers said they drink 1-2 sachets per day while the rest takes it in bottle. Most of this alcohol drinkers said they have been taking it since their teen age. [16] have confirmed that $10 \mathrm{~g}$ (roughly one drink) of alcohol consumed per day on average. Also, Women who have 2-3 alcoholic drinks per day have a $20 \%$ higher risk of breast cancer compared to nondrinkers.

TABLE II: PHYSICAL ACTIVITIES BEFORE AND AFTER DIAGNOSIS

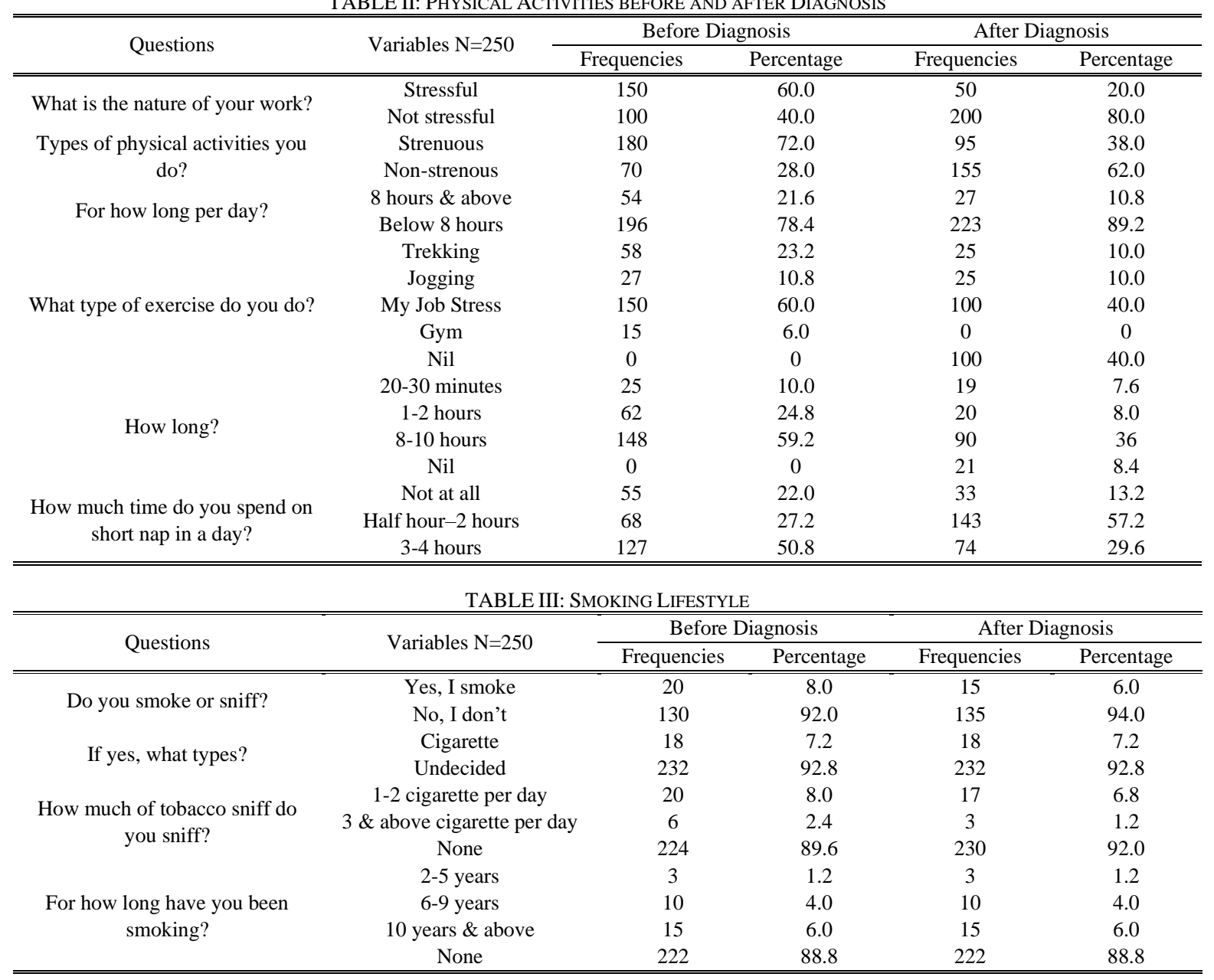

TABLE IV: ALCOHOL LIFESTYLE

\begin{tabular}{|c|c|c|c|c|c|}
\hline \multirow{2}{*}{ Questions } & \multirow{2}{*}{ Variables $N=250$} & \multicolumn{2}{|c|}{ Before Diagnosis } & \multicolumn{2}{|c|}{ After Diagnosis } \\
\hline & & Frequencies & Percentage & Frequencies & Percentage \\
\hline \multirow{2}{*}{ Do you take alcoholic drink? } & Yes, I drink & 95 & 38.0 & 90 & 36.0 \\
\hline & No, I don't & 155 & 62.0 & 160 & 64.0 \\
\hline \multirow{4}{*}{ If yes, what types? } & Pure alcohol & 10 & 4.0 & 9 & 3.6 \\
\hline & In beer & 17 & 6.8 & 15 & 6.0 \\
\hline & Mixed with bitters/Herbs & 73 & 29.2 & 76 & 30.4 \\
\hline & None & 150 & 60.0 & 150 & 60.0 \\
\hline \multirow{3}{*}{$\begin{array}{l}\text { How many bottles/sachets per } \\
\text { day? }\end{array}$} & $1-2$ sachets per day & 54 & 21.6 & 61 & 24.4 \\
\hline & Above 3 sachets per day & 29 & 11.6 & 20 & 8.0 \\
\hline & $1-3$ bottles per day & 11 & 4.4 & 10 & 4.0 \\
\hline \multirow{4}{*}{$\begin{array}{c}\text { For how long you have been } \\
\text { drinking? }\end{array}$} & None & 156 & 62.4 & 159 & 63.6 \\
\hline & Few years ago, & 10 & 4 & 25 & 10.0 \\
\hline & Since Teenager & 70 & 28 & 25 & 10.0 \\
\hline & None & 170 & 68 & 100 & 40.0 \\
\hline
\end{tabular}

From Table V, before the diagnosis above half of the respondents ate four times daily while after diagnosis with breast cancer only half ate thrice daily. This could be because of the pain and emotional trauma that comes with diagnosis with the disease which most times result in anorexia or lack of appetite. Above four-fifth of the respondents ate more of carbohydrates before and after diagnosis. This may be indicative of the most abundant and readily available food stuff in the area where the study was conducted as most of them said they can eat yam flour all throughout the day.
Before diagnosis, a little below half of the respondents rarely eat vegetables while after diagnosis half rarely eat vegetables. This suggests that even though some eat vegetables, yet it does not seem to be palatable to the respondents. Previous studies have shown that dietary intakes low in fibre may also be a pre-disposing factor [17] in a systematic review discovered that the incidence and prevalence of cancer was greater amongst group of people consuming low fibre diet. Before diagnosis about two-third of the respondents eat meat all the time, while there was a slight reduction in the 
percentage of those who eat meat after being diagnosed.

From Table VI, close to all the respondents have breast fed before and after diagnosis. Before diagnosis, more than half breastfed for 3-6 months, and the few remaining bread fed for 7-10 months and above 10 months before diagnosis while after diagnosis all the respondents' breastfed for 3-6 months. This could be as a result of the pain and structural changes associated with breast cancer. More than half of the respondents said they do not use any contraceptives before and after diagnosis. Amongst the few who use contraceptives, a greater number of them use injectable followed by hormonal implants and then pills and barrier method. For mothers, breastfeeding has been reported to confer lower risk of breast and ovarian carcinoma, greater postpartum weight loss and decreased blood pressure compared with no breastfeeding [18].

From Table VII, almost all the respondents undergo stress before and after diagnosis. Before diagnosis, about two-third cope with stress by using pain relief drugs, while after diagnosis there was an increase in the percentage of those who use pain relief drugs to cope with stress. About two-third of the respondents said they go through emotional stress but less than half of them cope with this by weeping and doing nothing, respectively. Life events, like death of husband or divorce, were the most frequently studied with a trend towards validating a link between stress and breast cancer. The most surprising positive study was the British one published by Chen who reported an $\mathrm{OR}=11,6$ for women subject to severe stress

TABLE V: DIETARY INTAKE BEFORE AND AFTER DIAGNOSIS

\begin{tabular}{|c|c|c|c|c|c|}
\hline \multirow{2}{*}{ Questions } & \multirow{2}{*}{ Variables $\mathrm{N}=250$} & \multicolumn{2}{|c|}{ Before Diagnosis } & \multicolumn{2}{|c|}{ After Diagnosis } \\
\hline & & Frequencies & Percentage & Frequencies & Percentage \\
\hline \multirow{3}{*}{$\begin{array}{l}\text { How many times do you eat } \\
\text { per day? }\end{array}$} & Twice & 28 & 11.2 & 127 & 50.8 \\
\hline & Thrice & 72 & 28.8 & 97 & 38.8 \\
\hline & Four times daily & 150 & 60.0 & 26 & 10.4 \\
\hline \multirow{2}{*}{$\begin{array}{l}\text { What type of food do you } \\
\text { like eating? }\end{array}$} & More Carbohydrates & 212 & 84.8 & 210 & 84.0 \\
\hline & More proteins & 38 & 15.2 & 40 & 16.0 \\
\hline \multirow{3}{*}{$\begin{array}{l}\text { How often do you eat } \\
\text { vegetables? }\end{array}$} & Most times & 50 & 20.0 & 52 & 20.8 \\
\hline & Rarely & 120 & 48.0 & 125 & 50.0 \\
\hline & I don't like it & 80 & 32.0 & 73 & 29.2 \\
\hline \multirow{4}{*}{ How often do you eat meat? } & All the time & 163 & 65.2 & 160 & 64.0 \\
\hline & Rarely & 65 & 26.0 & 65 & 26.0 \\
\hline & I don't eat meat & 22 & 8.8 & 25 & 10.0 \\
\hline & Cow meat & 129 & 51.6 & 119 & 47.6 \\
\hline \multirow{2}{*}{ What type of meat? } & Pork meat & 91 & 36.4 & 88 & 35.2 \\
\hline & $\begin{array}{l}\text { White meat (Chicken, } \\
\text { turkey, bush meat) }\end{array}$ & 30 & 12.0 & 42 & 16.8 \\
\hline \multirow{3}{*}{$\begin{array}{l}\text { How often do you take } \\
\text { fruits? }\end{array}$} & Most times & 141 & 56.4 & 141 & 56.4 \\
\hline & Rarely & 100 & 40.0 & 102 & 40.8 \\
\hline & I don't eat fruits & 9 & 3.6 & 7 & 2.8 \\
\hline \multirow{3}{*}{$\begin{array}{l}\text { How often do you take soya } \\
\text { bean product? }\end{array}$} & Always & 100 & 40.0 & 100 & 40.0 \\
\hline & Rarely & 125 & 50.0 & 125 & 50.0 \\
\hline & I don't eat soya product & 25 & 10.0 & 25 & 10.0 \\
\hline \multirow{2}{*}{$\begin{array}{l}\text { Do you like eating fried } \\
\text { food? }\end{array}$} & Yes & 177 & 29.2 & 168 & 67.2 \\
\hline & No & 73 & 70.8 & 82 & 32.8 \\
\hline
\end{tabular}

TABLE VI: BREASTFEEDING AND USE OF CONTRACEPTIVES

\begin{tabular}{|c|c|c|c|c|c|}
\hline \multirow{2}{*}{ Questions } & \multirow{2}{*}{ Variables $\mathrm{N}=250$} & \multicolumn{2}{|c|}{ Before Diagnosis } & \multicolumn{2}{|c|}{ After Diagnosis } \\
\hline & & Frequencies & Percentage & Frequencies & Percentage \\
\hline \multirow{2}{*}{ Have you ever breast fed a baby? } & Yes, I have & 130 & 92.0 & 15 & 6.0 \\
\hline & No, I haven't & 20 & 8.0 & 135 & 94.0 \\
\hline \multirow{3}{*}{$\begin{array}{l}\text { How long did you breast feed your } \\
\text { child on the average? }\end{array}$} & 3-6 months & 171 & 68.4 & 250 & 100 \\
\hline & $7-10$ months & 59 & 23.6 & 0 & 0 \\
\hline & 10 months \& above & 20 & 8.0 & 0 & 0 \\
\hline \multirow{3}{*}{$\begin{array}{l}\text { Do you use any kind of family } \\
\text { planning method or contraceptives? }\end{array}$} & Yes & 101 & 40.4 & 101 & 40.4 \\
\hline & No & 149 & 59.6 & 149 & 59.6 \\
\hline & None & 150 & 60 & 149 & 59.6 \\
\hline \multirow{4}{*}{$\begin{array}{c}\text { What family planning } \\
\text { method/contraceptive do you use? }\end{array}$} & Pills & 14 & 5.6 & 14 & 4.0 \\
\hline & Injectable & 52 & 20.8 & 53 & 21.2 \\
\hline & Hormonal implants & 4 & 1.6 & 4 & 1.6 \\
\hline & Barrier & 30 & 12.0 & 30 & 12.0 \\
\hline
\end{tabular}

TABLE VII: STRESS

\begin{tabular}{|c|c|c|c|c|c|}
\hline \multirow{2}{*}{ Questions } & \multirow{2}{*}{ Variables $\mathrm{N}=250$} & \multicolumn{2}{|c|}{ Before Diagnosis } & \multicolumn{2}{|c|}{ After Diagnosis } \\
\hline & & Frequencies & Percentage & Frequencies & Percentage \\
\hline \multirow{2}{*}{$\begin{array}{l}\text { I undergo physical exhaustion or } \\
\text { stress. }\end{array}$} & Most often & 130 & 92.0 & 15 & 6.0 \\
\hline & Not often & 20 & 8.0 & 135 & 94.0 \\
\hline \multirow{2}{*}{$\begin{array}{l}\text { I do cope or fix physical } \\
\text { exhaustion or stress. }\end{array}$} & Rest & 56 & 22.4 & 18 & 7.2 \\
\hline & Pain relief drug & 194 & 77.6 & 232 & 92.8 \\
\hline \multirow{2}{*}{$\begin{array}{l}\text { I undergo psychological or } \\
\text { emotional stress. }\end{array}$} & Most often & 190 & 76.0 & 190 & 76.0 \\
\hline & Less often & 60 & 24 & 60 & 24.0 \\
\hline \multirow{4}{*}{ I cope or fix emotional stress. } & Weep & 59 & 23.6 & 59 & 23.6 \\
\hline & Rest & 41 & 16.4 & 41 & 16.4 \\
\hline & Diversional therapy & 50 & 20.0 & 50 & 20.0 \\
\hline & Nothing & 100 & 40.0 & 100 & 40.0 \\
\hline
\end{tabular}


C. Measuring the Association of BMI, Waist Hip Ratio, Obesity with Lifestyle Variables amongst Respondents.

\section{1) Hypothesis}

The null hypothesis "There is no significant association between parity and selected anthropometric measurements (BMI, WHR, obesity)" was rejected at $\mathrm{F}=29.4, \mathrm{p}>0.05$. Hence there is no significant relationship between BMI, WHR, obesity and parity. This suggests that parity has no significant statistical effect on the BMI, WHR and obesity status of the respondents. This finding is not consistent with the findings of [20] who opined that age at menarche, first childbirth, and menopause; parity; number of breast biopsies done in the past; histological findings of atypical hyperplasia or lobular carcinoma in situ in breast tissue; use of oral contraceptive pills and nulliparity, were factors predisposing breast cancer.

The null hypothesis "There is no significant association between lifestyle variables and selected anthropometric measures (BMI, WHR, obesity)" was rejected at F $=29.4$, $\mathrm{p} \leq 0.05$. Hence, there is a significant association between BMI, WHR, obesity and selected lifestyle variables. This implies that lifestyle variables had a significant statistical effect on the BMI, WHR and obesity status of breast cancer patients. This is consistent with the findings of [21] who described the association of high BMI with breast cancer and went on to explain that all these are the product of what we consume as documented in most recent studies that have shown a rising trend in incidence in hitherto low incidence areas of Africa and Asia due largely to changing dietary lifestyle, use of hormone replacement therapy (HRT) in the urban areas, obesity and better reporting of the disease.

The null hypothesis "There is no significant association between selected anthropometric measurements (BMI, WHR, obesity) and selected lifestyle variables before and after diagnosis" was rejected at $\mathrm{F}=36.3, \mathrm{p} \leq 0.05$. Hence there is a significant association between BMI, WHR, obesity and selected lifestyle variables before and after diagnosis. This suggests that lifestyle variables are extraordinarily strong parameters that determine the nutritional status of the body as well as the obesity status regardless of the morbid or premorbid state [6] noted that body mass index (BMI) and waist hip ratio (WHR) known as parameters used to describe the nutritional status of an individual and to determine obesity in adults has been associated of recent with breast cancer.

\section{CONCLUSION}

Lifestyle variables were found to have significant influence on the anthropometric measures of the body of breast cancer patients regardless of their morbid or premorbid state. This as well has been implicated in the initiation and progression of breast cancer. The findings of this study have been consistent along this line with major recent findings in the literature. Even though a little modification of certain lifestyles were recorded after respondents were being diagnosed with breast cancer, this undeniably could be as a result of fear of the outcome of the disease, personal effort to get knowledge or the impact of health education from care givers. However, the anthropometric measures that highlights or suggests the obesity status becomes extremely large as a result of ignorance of certain lifestyle variables that needed to have been placed in a check or within limit of expression, this calls for strategic actions. Also, parity was noted not to have any influence on the body's anthropometric measures. This disparity in result could be as a result of the difference in geographical location which defines the place of genetic and environmental influence on the body's structure and measures. It is therefore imperative to take cognizance of genetic and environmental influence on the body's anthropometric measures as well as obesity status in the search for how lifestyle changes influence breast cancer.

\section{REFERENCES}

[1] T., Soini, R., Hurskainen, S., Grenman, J., Maenpaa, J., Paavonen, E., Pukkala. Cancer risk in women using the levonorgestrel-releasing intrauterine system in Finland. Obstet Gynecol. 2014;124: 292-299.

[2] B.K Edwards, A.M Noone, A.B Mariotto, et al: Annual Report to the Nation on the status of cancer, 1975-2010, featuring prevalence of comorbidity and impact on survival among persons with lung, colorectal, breast, or prostate cancer. Cancer 120:1290-1314, 2014.

[3] Cancer Genome Atlas Network. Comprehensive molecular portraits of human breast tumours. Nature. 2012;490: 61-70.

[4] P.S Agbo, A. Khalid, M. Oboirien. Clinical Presentation, Prevalence and Management of Breast Cancer in Sokoto, Nigeria. J Womens Health Care 2014; 3:149.

[5] World Health Organization. Breast Cancer Facts \& Figures 2017-2018. WHO, inc 2017.

[6] T. Zhang, R. Yan, Q. Chen, et al Body mass index, waist-to-hip ratio and cognitive function among Chinese elderly: a cross-sectional study BMJ Open 2018 ;8: e022055. doi: 10.1136/bmjopen-2018-022055.

[7] S. Cunningham-Rundles., H. Lin., D. Ho-Lin., A. Dnistrian., B.R Cassileth., B. R \& J.M. Perlman. Role of nutrients in the development of neonatal immune response. Nutrition Reviews, (2009) 67 Suppl 2, S152.

[8] S. Jung, M. Wang, K. Anderson, et al. Alcohol consumption and breast cancer risk by estrogen receptor status: in a pooled analysis of 20 studies. Int J Epidemiol. 2016;45: 916-928.

[9] S.M George, et al. Central adiposity after breast cancer diagnosis is related to mortality in the Health, Eating, Activity, and Lifestyle study. Breast Cancer Res Treat. (2014) 146, 647-655.

[10] A.J. White, A.A D’Aloisio, H.B Nichols, L.A DeRoo, D.P Sandler. Breast cancer and exposure to tobacco smoke during potential windows of susceptibility. Cancer Causes Control. 2017;28: 667-675.

[11] M. Dianatinasab, M.F. M. Mohammadianpanah, and M. ZareBandamiri, Impact of social and clinical factors on diagnostic delay of breast cancer: A Cross-sectional Study. Medicine.2016: 95:38(e4704) http://dx.doi.org/10.1097/MD.0000000000004704.

[12] A.M Brunner, H. Sadrzadeh, Y. Feng, B.J Drapkin, K.K Ballen, E.C Attar, et al. Association between baseline body mass index and overall survival among patients over age 60 with acute myeloid leukemia. Am J Hematol 2013; 88:642-6.

[13] C. Pizot, M. Boniol, P. Mullie, et al. Physical activity, hormone replacement therapy and breast cancer risk: A meta-analysis of prospective studies. Eur J Cancer. 2016;52: 138-154.

[14] J.S Hildebrand, S.M Gapstur, P.T Campbell, M.M Gaudet, and A.V Patel. Recreational physical activity and leisure-time sitting in relation to postmenopausal breast cancer risk. Cancer Epidemiol Biomarkers Prev. 2013;22: 1906-1912.

[15] L. Dossus, M.C Boutron-Ruault, R. Kaaks, et al. Active and passive cigarette smoking and breast cancer risk: results from the EPIC cohort. Int J Cancer. 2014;134: 1871-1888.

[16] Y. Liu, N. Nguyen, and G.A Colditz. Links between alcohol consumption and breast cancer: a look at the evidence. Women's Health (London, England). 2015;11: 65-77.

[17] J.M Gierisch, R.R Coeytaux, R.P Urrutia, L.J Havrilesky, P.G Moorman, and W.J Lowery. Oral contraceptive Use and Risk of Breast, Cervical, Colorectal, and Endometrial Cancers: A Systematic Review. Cancer Epidemiol Biomarkers prev 2013; 22:1931-43.

[18] S. Jung, M. Wang, K. Anderson, et al. Alcohol consumption and breast cancer risk by estrogen receptor status: in a pooled analysis of 20 studies. Int J Epidemiol. 2016;45: 916-928.

[19] C.M. Chiriac, A. Baricz, E. Szekeres, et al. Microbial Composition and Diversity Patterns in Deep Hyperthermal Aquifers from the Western 
Plain of Romania. Microb Ecol 75, 38-51 (2018). https://doiorg.ezproxy.bcu.ac.uk/10.1007/s00248-017-1031-x.

[20] O. Oguntoke. Spatial and socio-demographic disparities of cancer morbidity in Nigeria: Patterns and factors. GEOGRAFIA OnlineTM Malaysian Journal of Society and Space 10 issue 1 (25 - 35) 35 (C) 2014 ISSN 2180-2491.

[21] C.I Li, E.F Beaber, M.T Tang, P.L Porter, J.R Daling, and K.E Malone. Effect of depo-medroxyprogesterone acetate on breast cancer risk among women 20 to 44 years of age. Cancer Res. 2012;72: 2028-2035.

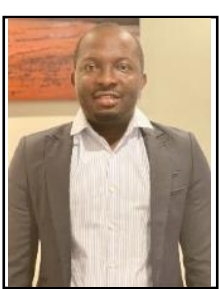

Emmanuel O. Adesuyi was born in Lagos, Nigeria. He received a bachelor's degree in nursing science from the Ladoke Akintola University of Technology, Ogbomoso, Nigeria, in 2012, and master's degree in public health, Epidemiology and Infection Control from the same university.

$\mathrm{He}$ had special interest in Oncology. He is registered with the nursing and midwifery council of Nigeria as a Registered nurse and Registered midwife. He is also a registered general nurse in the UK. He started his research career as a student in the university as well as an educator working alongside with other researchers on RNA virus and Neoplastic growths. He has a number of publications and co-authored books credited to him in reputable journals.

Mr Adesuyi's current research interests include latent angiogenesis initiators, cancer metastasis, cancer vaccines, nursing education, telenursing and other public health issues. He also joined the editorial board of the Journal of Tumour International (Omics) in 2016 and has peer reviewed many manuscripts now published in reputable journals. He is the Chief Operating Officer of the Institute of Nursing Research, Nigeria. He is also currently a Doctoral Research scholar and assistant lecturer at Birmingham City University, UK. 